OPEN ACCESS

Edited by:

Alberto Rainer,

Università Campus Bio-Medico, Italy

Reviewed by:

Francesca Cavalieri,

University of Melbourne, Australia

Filippo Rossi,

Politecnico di Milano, Italy

*Correspondence:

Heike Boehm

heike.boehm@mpimf-

heidelberg.mpg.de

${ }^{\dagger}$ Present address:

Burcu B. Minsky,

Department of Biological Sciences,

Smith College, Northampton, MA,

United States

Specialty section:

This article was submitted to

Integrative Physiology,

a section of the journal

Frontiers in Physiology

Received: 22 February 2018

Accepted: 10 July 2018

Published: 07 August 2018

Citation:

Zapp C, Minsky BB and Boehm H

(2018) Tuning RGD Motif

and Hyaluronan Density to Study

Integrin Binding.

Front. Physiol. 9:1022.

doi: 10.3389/fphys.2018.01022

\section{Tuning RGD Motif and Hyaluronan Density to Study Integrin Binding}

\author{
Cornelia Zapp ${ }^{1,2}$, Burcu B. Minsky ${ }^{1+}$ and Heike Boehm ${ }^{1,2 *}$ \\ ${ }^{1}$ Department of Cellular Biophysics, Max Planck Institute for Medical Research, Heidelberg, Germany, ${ }^{2}$ Physical Chemistry, \\ Heidelberg University, Heidelberg, Germany
}

Well-controlled surfaces with immobilized substrates enable novel approaches to investigate specific aspects of biological processes related to cell adhesion or motility. A subset of integrins, cellular transmembrane glycoproteins, recognize the evolutionarily conserved tripeptide sequence RGD, and anchor cells to their surrounding proteins as well as mediate bidirectional signaling. In this study, the main question was how co-presentation of hyaluronan $(\mathrm{HA})$, an essential component of the extracellular matrix (ECM), and the RGD motif affect integrin binding. We report a method to prepare selfassembled monolayers on gold surfaces, co-presenting the cell adhesive RGD motif and small HA molecules, to investigate integrin containing proteoliposome binding. This technique enables an independent adjustment of the RGD motif and HA density while maintaining a passivating background: Layer formation and subsequent interactions with $\alpha_{\| b} \beta_{3}$ integrins, which are reconstituted in liposomes, was monitored by labelfree quartz crystal microbalance with dissipation monitoring (QCM-D). Exceeding a critical RGD motif density of $40 \%$ results in enhanced binding of proteoliposomes. Copresentation studies with varying $H A$ and constant RGD motif density demonstrate that marginal amounts of HA are sufficient to prevent integrin binding. These findings are of specific importance in relation to cancer cell microenvironments, which show highly enriched HA in the surrounding ECM to reduce adhesion properties.

Keywords: QCM-D, hyaluronan, integrins, cell adhesion, proteoliposomes

\section{INTRODUCTION}

Nature has generated well-adapted processes and materials through natural selection. Thus, nature in its remarkable diversity provides an extraordinary collection of strategies. These can be exploited as a source of inspiration and adopted for biological applications. As such, the interdisciplinary field of biomimetics research encompasses many specialty areas in biology, materials science, and nanotechnology. The fundamental idea is to generate synthetic systems to mimic biological concepts or to accomplish biological tasks. One approach to utilize this synthetic biological concept is the "bottom-up" approach, in which a minimal number of synthetic or biological molecules are combined to realize a desired function (Tu and Tirrell, 2004; Benner and Sismour, 2005; Purnick and Weiss, 2009). Molecular biomaterials can be fabricated in a "bottom-up" approach, in which molecules adapt a defined arrangement and consequently produce novel macromolecular assemblies. Molecular assembly can be applied to modulate surface properties of a material's interface, where chemical, physical, and biological processes 
are maintained. Surfaces are of foremost importance in biological systems, since surface-cell interactions modulate how cells attach to the material. Specifically modified surfaces may serve as a research platform to study specific aspects of cell interaction.

The extracellular matrix (ECM) is a complex dynamic meshwork consisting of diverse macromolecules, which are secreted by the embedded cells within the tissue and provide biochemical and structural support. Cells sense chemical, topographic and mechanical features via specific cellular receptors and mediate the assembling of adhesion complexes to transfer information via signaling pathways (Geiger and Yamada, 2011; Jansen et al., 2017). Thus, cell adhesion to the surrounding matrix and neighboring cells plays a key role in many cellular processes including survival, differentiation and proliferation (Berrier and Yamada, 2007). Integrins are the most abundant and fundamental matrix receptors on animal cells (Mecham, 2011). These transmembrane heterodimeric glycoproteins fulfill two main functions: (1) attachment of cells to the ECM and (2) inducing bidirectional signal transduction between the ECM and cells (Streuli, 2016; Gauthier and Roca-Cusachs, 2018). A prevalently surface-displayed and evolutionarily conserved RGD motif consists of the three amino acids arginine, glycine, and aspartate. The RGD motif is present in various proteins of the ECM, for instance fibronectin, vitronectin, and fibrinogen (Mecham, 2011). A subset of integrins specifically recognize RGD repeats to anchor cells to the ECM and mediate bidirectional signaling. Therefore, studying cell adhesion demands precise control of RGD immobilization on the artificial surfaces to focus mainly on the surface properties required for cellular interactions via integrins and prevent non-specific protein attachment.

The non-sulfated glycosaminoglycan hyaluronan (HA) is a major non-proteinaceous component of the ECM and is formed of repeating disaccharide units of glucuronic acid and $\mathrm{N}$-acetyl glucosamine. HA provides structural support, maintains tissue hydration, and serves as a lubricant in certain tissues (Dicker et al., 2014). HA interacts with a large number of HA-binding proteins (hyaladherins), matrix components and cells. Its temporal and spatial distribution as well as size plays critical roles in numerous biological processes, e.g., wound healing, inflammation and tumor progression (Dicker et al., 2014). Although HA is an essential component of extracellular structures and is reported to contribute to diverse cellular functions, little is known about its role in cellular adhesion processes. It has been reported, that HA can have both adhesive and anti-adhesive properties as well as promote cell detachment (Evanko et al., 2007; Cao et al., 2009). Moreover, showing that inhibition of $\mathrm{CD} 44$ on hematopoietic progenitor cells prevents rolling and adhesion to an HA-coated surface (Hanke et al., 2014) or that HA mediates also early, long-ranging adhesive interactions between cells and the surrounding surface, which precede integrin-mediated adhesion and formation of focal adhesions (Zimmerman et al., 2002; Zaidel-Bar et al., 2004) demonstrates the importance of HA specific interactions. In order to understand the role of HA in the dynamic process of cell adhesion, we aim to establish a synthetic model with reduced complexity, giving us the opportunity to focus on the repulsive forces of HA.
Numerous studies have applied the chemical functionalization of surfaces with desired properties to study the effect on cell structures, metabolism, viability or proliferation among others (Yao et al., 2013; Jeon et al., 2014; Ventre and Netti, 2016). One approach for the chemical functionalization of surfaces is the formation of self-assembled monolayers (SAMs) on gold surfaces through thiol residues (Love et al., 2005). Thereby precise control over the properties of the designed biological interfaces can be exerted by the molecular structure and the surrounding environment.

Alkanethiols terminated with oligo(ethylene glycol) moieties (OEG-alkanethiols) form SAMs on gold surfaces, which are resistant to unspecific protein adsorption. These surfaces have been exploited in several studies including cell adhesion or stem cell differentiation (Tidwell et al., 1997; Arima and Iwata, 2015; Hao et al., 2016; Almeida and Shukla, 2017).

The well-defined surfaces employed in this study were prepared according to the protocol published by Minsky et al. (2016), in which a controlled immobilization strategy in a twolayer system, simultaneously prevents unspecific protein binding and enables adjusting of the immobilization density on a surface. For this purpose SAMs are formed spontaneously on gold surfaces by co-adsorption of two functionalized oligo(ethylene glycol)-alkanethiols and unfunctionalized OEG-alkanethiols. By tuning the ratio of the two components, the density of the surfacedisplayed motif can be defined while a passivating background is maintained.

Work in our lab has focused on designing a bioinspired and well-controlled artificial integrin adhesion model system, in which surfaces, including the RGD binding motif and/or HA on an otherwise passivating background layer represent ECM mimetic, and reconstituted transmembrane integrins within lipid vesicles represents cell mimetic. Integrins form non-covalently associated heterodimeric complexes of an $\alpha$ - and a $\beta$-subunit, each having a large extracellular domain, a membrane spanning region and a short cytoplasmic domain (Hynes, 2002; Barczyk et al., 2010). In order to resemble the natural arrangement, isolated $\alpha_{\mathrm{IIb}} \beta_{3}$ integrins were reconstituted into liposomes, built up of amphiphilic molecules forming phospholipid bilayers and surrounding an aqueous unit (Akbarzadeh et al., 2013).

Within this study large unilamellar liposomes and liposomes with reconstituted $\alpha_{\mathrm{IIb}} \beta_{3}$ integrin (hereinafter referred to as proteoliposomes) were prepared by detergent removal (Erb et al., 1997). The aim of this study is to address the question of how co-presentation of HA and the RGD motif in varying densities impacts the attachment of integrins.

\section{MATERIALS AND METHODS}

\section{Chemicals}

Purified L- $\alpha$-phosphatidylcholine (eggPC) and L$\alpha$-phosphatidyl-DL-glycerol (eggPG) were purchased from Avanti Lipids Polar Inc. (Alabaster, AL, United States). Biobeads SM-2 (20-50 mesh size) were obtained from BioRad Laboratories Inc. (Hercules, CA, United States). Triton $\mathrm{X}-100$, sodium cyanoborohydride, and propargylamine 
were purchased from Sigma-Aldrich (Steinheim, Germany). Hyaluronic acid sodium salt $\left(\mathrm{M}_{\mathrm{r}}=10 \mathrm{kDa}\right.$, sHA) was procured from LifeCore Biomedial (Chaska, MN, United States). $\mathrm{HS}-(\mathrm{CH})_{11}-\mathrm{EG}_{3}-\mathrm{OH} \quad\left(\mathrm{EG}_{3} \mathrm{OH}\right)$ and $\mathrm{HS}-(\mathrm{CH})_{11}-\mathrm{EG}_{6}-\mathrm{N}_{3}$ $\left(\mathrm{EG}_{6} \mathrm{~N}_{3}\right)$ were obtained from Prochimia (Sopot, Poland). Alkylated RGD peptide (sequence: GRGDSP) was purchased from Peptide Specialty Laboratories GmbH (Heidelberg, Germany). Dialysis tube (MWCO: 3,500 Da) was purchased from VWR (Radnor, PA, United States). Integrin $\alpha_{\text {IIb }} \beta_{3}$ was extracted from outdated human blood platelets obtained by the Red Cross Germany, according to the protocol from Müller et al. with modifications (Müller et al., 1993; Hu et al., 2000).

\section{Proteoliposome Preparation by Detergent Removal}

The protein was reconstituted into proteoliposomes according to the general procedure developed by Erb et al. (1997). Typically, an equimolar lipid mixture of eggPC/eggPG ( $0.43 \mu \mathrm{mol}$ each) was vacuum - dried and resuspended in $1 \mathrm{~mL}$ buffer $\mathrm{B}(20 \mathrm{mM}$ TRIS, $50 \mathrm{mM} \mathrm{NaCl}, 1 \mathrm{mM} \mathrm{CaCl}$, and $0.1 \%$ Triton $\mathrm{X}-100$ at $\mathrm{pH}$ 7.4). For the preparation of proteoliposomes, the lipids were solubilized in $827 \mu \mathrm{L}$ buffer B and $174 \mu \mathrm{L}$ integrin $\alpha_{\text {IIb }} \beta_{3}$ $(0.23 \mathrm{mg} / \mathrm{mL})$ was added to a final protein:lipid ratio of 1:5,000. Afterwards, the mixture was incubated at $37^{\circ} \mathrm{C}$ for $2 \mathrm{~h}$ under shaking. The detergent Triton X-100 was removed with $50 \mathrm{mg}$ Bio-Beads SM-2 under stirring for $3.5 \mathrm{~h}$. After removing the Bio-Beads SM-2, the detergent removal step was repeated. The obtained solution was stored at $4^{\circ} \mathrm{C}$ for a total maximum of $24 \mathrm{~h}$. Before usage the resulting vesicles were processed by extrusion with a nominal $100 \mathrm{~nm}$ pore membrane (Whatman, Maidstone, United Kingdom) 11 times using a mini-extruder apparatus (Avanti Polar Lipids Inc., Alabaster, AL, United States). DLS measurements show an average size of $137.7 \pm 41.9 \mathrm{~nm}$ for pure liposomes and $162.1 \pm 41.7 \mathrm{~nm}$ for proteoliposomes. Vesicles were generally prepared at a nominal lipid concentration of $\sim 0.675 \mathrm{mg} / \mathrm{mL}$, and then diluted $1: 20$ in $20 \times$ activation buffer $(1 \times$ activation buffer: $50 \mathrm{mM} \mathrm{NaCl}, 20 \mathrm{mM}$ TRIS, $1 \mathrm{mM}$ $\mathrm{CaCl}_{2}, 1 \mathrm{mM} \mathrm{MgCl}$, and $1 \mathrm{mM} \mathrm{MnCl}_{2}, \mathrm{pH}$ 7.4) before the experiment.

\section{Sample Preparation for Formation of a Functionalized Self-Assembled Monolayer}

Click reaction was performed using TRIS buffer (100 mM, pH 8.5), ascorbic acid (100 mM), EG $\mathrm{N}_{3}(150 \mu \mathrm{M})$ and alkylated RGD peptide sequence $(480 \mu \mathrm{M})$ in the presence of $1 \mathrm{mM} \mathrm{CuSO}_{4}$. After $1.5 \mathrm{~h}$ at RT the reaction was stopped by adding EDTA $(1 \mathrm{mM})$ to chelate copper. Mixtures with different ratios were prepared by diluting $\mathrm{EG}_{6} \mathrm{RGD}$ with $\mathrm{EG}_{3} \mathrm{OH}$ and adjusted to a total thiol concentration of $100 \mu \mathrm{M}$ in passivation buffer. Surfaces were prepared by immobilization of this OEG mixture on the gold surface of the quartz crystal microbalance with dissipation monitoring (QCM-D) sensor, followed by a final washing step in passivation buffer.

\section{Quartz Crystal Microbalance With Dissipation Monitoring Measurements}

For QCM-D experiments a fully automated Q-sense Omega Auto instrument (Biolin Scientific AB, Västra Frölunda, Sweden) with gold-coated quartz crystal electrodes (QSX301, Q-sense, AT-cut, 4.95 MHz, Biolin Scientific AB, Västra Frölunda, Sweden) was used. The system was operated in flow mode with a flow rate of $20 \mu \mathrm{L} / \mathrm{min}$ at $24^{\circ} \mathrm{C}$. Frequency and dissipation data were collected from six overtones $(n=3,5,7,9,11,13)$. Prior to use the electrodes were cleaned in a $5: 1: 1$ solution of water, $30 \%$ hydrogen peroxide and $25 \%$ ammonia at $75^{\circ} \mathrm{C}$ for $10 \mathrm{~min}$ and activated in an UV/Ozone cleaner (ProCleaner, Bioforce Nanosciences, Ames, IA, United States) for $10 \mathrm{~min}$. The Omega Auto includes a fully automated sample handling of four sensors in parallel and each sequence of an experiment was performed in duplicates. Changes in dissipation and normalized frequency, $\Delta f=\Delta f n / n$, of the seventh overtone $(n=7)$ are presented in the graphs. Frequency and dissipation changes were calculated by averaging over the last 5 min of the buffer wash before adding the samples and the final buffer wash. Buffers used as baselines were passivation buffer ( $50 \mathrm{mM} \mathrm{NaCl}, 20 \mathrm{mM}$ TRIS, $1 \mathrm{mM} \mathrm{CaCl}_{2}$, and $1 \mathrm{mM} \mathrm{MgCl}_{2}, \mathrm{pH} 7.4$ ), activation buffer (passivation buffer with $\left.1 \mathrm{mM} \mathrm{MnCl}_{2}, \mathrm{pH} 7.4\right)$, and TRIS buffer (100 mM, pH 8.5).

\section{Synthesis of End-Alkylated Hyaluronan}

Functionalization at the reducing $N$-acetylglucosamine unit of sHA was performed according to the protocol established by Lee et al. (2008). In short, $100 \mathrm{mg}$ sHA and propargylamine (523 mM) were dissolved in borate buffer $(20 \mathrm{~mL}, 100 \mathrm{mM}$, $\mathrm{pH} 8.5)$ containing sodium chloride $(400 \mathrm{mM})$ for $2 \mathrm{~h}$ at RT. After adding sodium cyanoborohydride $(200 \mathrm{mM})$ the solution was stirred for $5 \mathrm{~d}$ at $40^{\circ} \mathrm{C}$. The mixture was dialyzed once against water, containing sodium chloride and hydrochloric acid, followed by water containing hydrochloric acid for $2 \mathrm{~d}$. Prior to storage at $-20^{\circ} \mathrm{C}$ the end-alkylated sHA was lyophilized.

\section{Preparation of a Dual-Functionalized Self-Assembled Monolayer}

For preparing the dual functionalized surfaces, a constant ratio of $\mathrm{EG}_{6} \mathrm{RGD}(40 \%)$ was mixed with $\mathrm{EG}_{3} \mathrm{OH}$ and $\mathrm{EG}_{6} \mathrm{~N}_{3}(0-100 \%$ $\mathrm{EG}_{6} \mathrm{~N}_{3}$ ). After immobilization of this OEG mixture on the gold surface of the QCM-D sensor, end-alkylated HA $(1.875 \mathrm{mg} / \mathrm{mL})$ was conjugated to the $\mathrm{EG}_{6} \mathrm{~N}_{3}$ in the presence of ascorbic acid $(100 \mathrm{mM})$ and CuSO4 $(1 \mathrm{mM})$ in TRIS buffer $(100 \mathrm{mM}, \mathrm{pH}$ 8.5). Finally, the surface was washed with TRIS buffer to remove unbound molecules.

\section{RESULTS AND DISCUSSION}

Within this study dual-functionalized surfaces were prepared by co-presenting the RGD motif and HA in varying densities on a passivating background. The average contour length of the short HA (sHA $<10 \mathrm{kDa}$ ) is around $24 \mathrm{~nm}$ and its radius of gyration is around $5.3 \mathrm{~nm}$ (Takahashi et al., 1999; Buhler and Boué, 2004). A mixture of OEGs, containing OEG-alkanethiol 


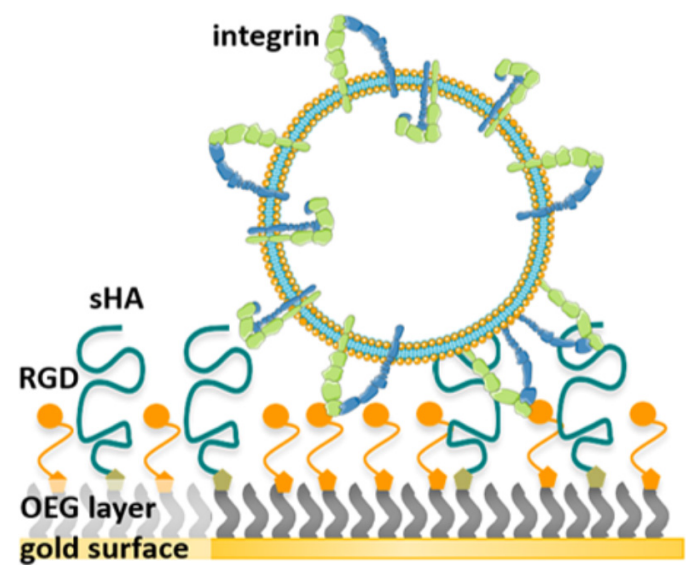

FIGURE 1 | Illustration of the working principle: First, a dual-functionalized SAM is prepared enabling independent adjustment of the sHA density and RGD binding motif density, respectively. Second, the binding of integrins reconstituted in liposomes to the RGD binding motif within these surfaces was assessed.

$\left(\mathrm{EG}_{3} \mathrm{OH}\right)$, OEG-alkanethiols functionalized with RGD motif (EG ${ }_{6}$ RGD), and OEG-alkanethiols with a terminal azide group $\left(\mathrm{EG}_{6} \mathrm{~N}_{3}\right)$, were immobilized on the gold surface. Subsequently, end-alkylated HA was conjugated to the OEG-azide group in the immobilized OEG layer directly on the surface via an in situ azide/alkyne cycloaddition reaction. This extended surface preparation approach facilitates the variation of the HA density and RGD density independently of each other, while a passivating background is maintained. Figure $\mathbf{1}$ illustrates the working principle. Following the surface preparation, the attachment of liposomes and proteoliposomes on these well-defined surfaces was monitored using QCM-D. QCM-D is a label-free, real-time measurement technique for monitoring molecular adsorption and/or interactions on various surfaces covering a quartz crystal. As a direct impact of mass adsorption, changes in frequency of the oscillating quartz crystal are detected (Dixon, 2008). An observed shift in the dissipation provides insights regarding the viscoelastic properties and rearrangements of the adlayer (Dixon, 2008).

\section{Critical RGD Motif Density for Binding Proteoliposomes}

The high-density presentation of RGD was achieved with a straightforward and fast method by first conjugating RGD to $\mathrm{EG}_{6} \mathrm{~N}_{3}$ via copper(I)-catalyzed azide-alkyne cycloaddition (CuAAC) and subsequently immobilizing on gold surfaces in the presence of $\mathrm{EG}_{3} \mathrm{OH}$ to adjust the density. As seen in the QCM-D profile, after proximately $30 \mathrm{~min}$ the decrease in frequency and increase in dissipation are stable, originating from adsorption of both OEG alkanethiols. After a subsequent washing step the frequency slightly increases and the dissipation decreases reaching a stable value indicating successful immobilization of

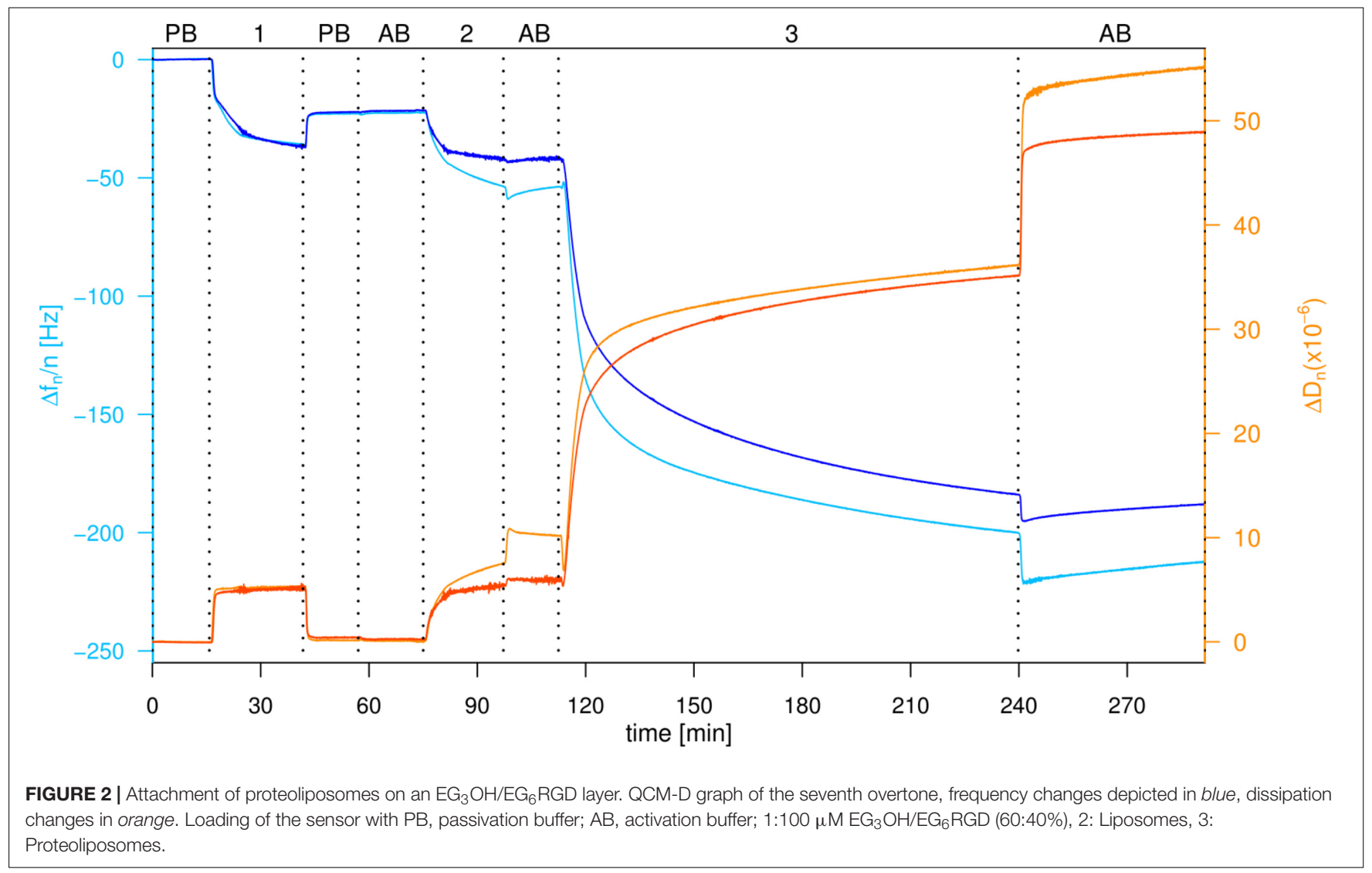


a dense OEG layer on the gold surface (Figure 2). When the buffer was changed from passivation buffer to the same buffer containing $2 \mathrm{mM}$ divalent ions $\left(1 \mathrm{mM} \mathrm{Mn}^{2+}\right.$ and $1 \mathrm{mM} \mathrm{Mg}^{2+}$, referred to as activation buffer) no change in frequency or dissipation was monitored. All further steps were performed in activation buffer since the affinity and specificity of integrins binding to the RGD motif is affected by the concentration of divalent ions (Zhang and Chen, 2012). As a control for unspecific attachment to the OEG and OEG-RGD layer, pure liposomes were washed over the modified surfaces. The frequency decreases again and the dissipation increases, indicating that liposomes adhere non-specifically and remain attached when washed with buffer. When proteoliposomes are washed over the modified surface, a frequency change as well as dissipation change is observed, which are even reinforced after a subsequent washing step. This observation indicates that the proteoliposomes stay intact and the integrins bind firmly to the RGD motif as they could not be removed by washing (Figure 2).

Based on this general experimental setup, the influence of the RGD motif density on the attachment of proteoliposomes was quantified. Modified surfaces were prepared with six different
RGD motif densities ranging from 0 to $100 \%$ according to the adjustable well-defined system outlined above.

In the initial SAM formation of the OEG layer, an increasing frequency change is observed at higher RGD motif densities. This correlation is effected by the amount of $\mathrm{EG}_{6} \mathrm{RGD}$, which has a molecular weight of $1,120 \mathrm{~g} / \mathrm{mol}$ and is consequently heavier than the $\mathrm{EG}_{3} \mathrm{OH}$ molecules (molecular weight $=671 \mathrm{~g} / \mathrm{mol}$ ). Dissipation changes, mainly between $0 \times 10^{-6}$ and $1 \times 10^{-6}$, indicate a rigid and well coupled OEG layer at all measured RGD densities (Figures 3A,D). Evaluation of the surface's unspecific binding activity demonstrates that bare liposomes attach unspecifically to some extent to the surface, independently of the RGD ratio. Thereby, the frequency and dissipation changes for all RGD concentrations fluctuate around $-41.82 \pm 20.88 \mathrm{~Hz}$ and $11.28 \times 10^{-6} \pm 5.48 \times 10^{-6}$, respectively (Figures 3B,E).

The subsequent attachment of proteoliposomes on the RGD motif functionalized surfaces was assessed in the next step. In general, decreasing frequency and dissipation values demonstrate a mass adsorption and formation of a viscoelastic adlayer, respectively. This indicates proteoliposome binding to the RGD motif on the surface via integrins. For

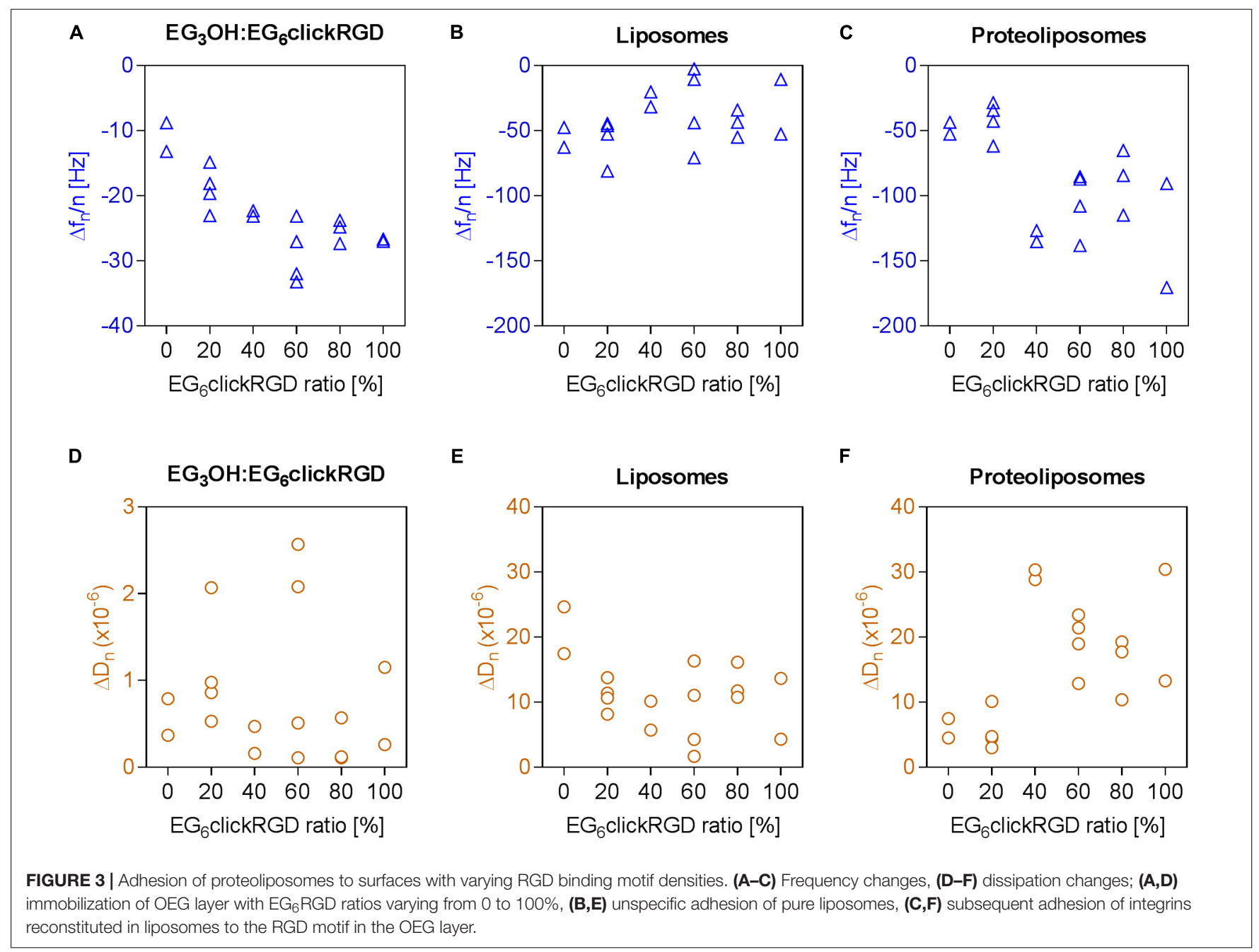



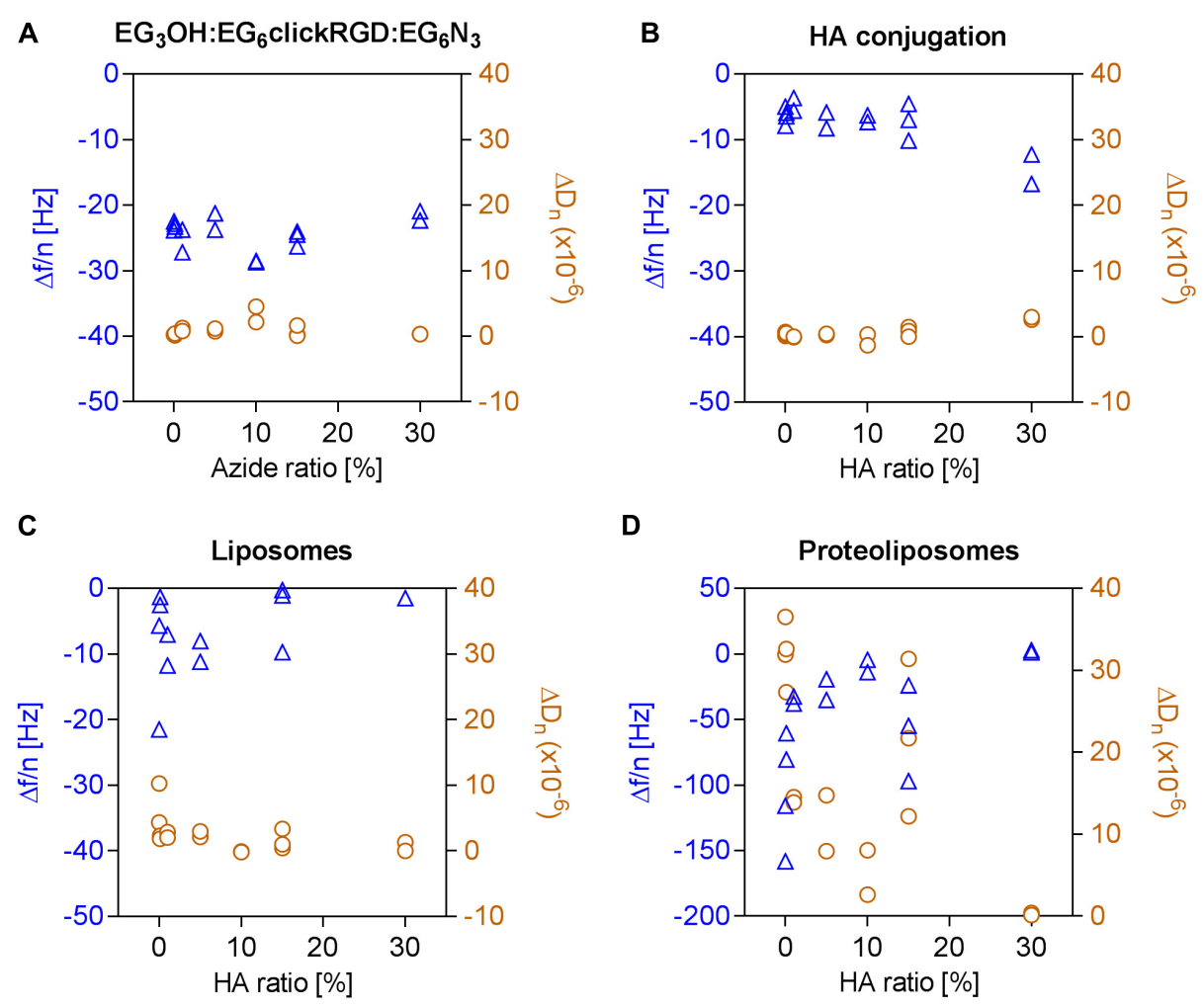

FIGURE 4 | Adhesion of proteoliposomes to surfaces with a constant RGD motif density and varying ratios of conjugated HA. Frequency changes depicted in blue triangles and dissipation changes in orange circles were calculated based on the seventh overtone. (A) Immobilization of OEGs bearing an azide group (0-30\%), (B) Followed by a conjugation of end-alkylated HA to the OEG layer by CuAAC, (C) Unspecific attachment of liposomes on the OEG layer, (D) Subsequent adhesion of proteoliposomes to the dual-functionalized surface.

an increased ratio of $\mathrm{EG}_{6} \mathrm{RGD}$ the graph shows biphasic curve characteristics (Figures 3C,F). In the first part, when the ratio of $\mathrm{EG}_{6} \mathrm{RGD}$ to $\mathrm{EG}_{3} \mathrm{OH}$ is 0 or $20 \%$ a frequency change of $43.98 \pm 11.02 \mathrm{~Hz}$ and dissipation shift of $5.72 \times 10^{-6} \pm 2.37 \times 10^{-6}$ occurs. Whereas in the second part, when the $\mathrm{EG}_{6} \mathrm{RGD}$ ratio exceeds or is equal to $40 \%$, a higher frequency shift of $-109.89 \pm 30.94 \mathrm{~Hz}$ and simultaneously higher dissipation change of $20.79 \times 10^{-6} \pm 7.04 \times 10^{-6}$ is detected. Based on these results an RGD motif density of $40 \%$ was employed for further experiments.

\section{Hyaluronan as Part of a Dual-Functionalized Surface Prevents Proteoliposome Binding}

In order to examine the adhesion of integrins in the presence of HA, dual-functionalized surfaces were prepared following the previously described procedure. This was achieved by conjugation of end-alkylated $\mathrm{HA}$ to an OEG layer, containing varying amounts of $\mathrm{EG}_{6} \mathrm{~N}_{3}$ and $\mathrm{EG}_{3} \mathrm{OH}$ and a constant ratio of $40 \% \mathrm{EG}_{6} \mathrm{RGD}$. The immobilization of the OEG layers caused a constant frequency change, fluctuating around $-24.25 \pm 2.33 \mathrm{~Hz}$, independently of the ratio of $\mathrm{EG}_{6} \mathrm{~N}_{3}$ with general low dissipation values $\left(0.96 \times 10^{-6} \pm 1.12 \times 10^{-6}\right)$. Directly after immobilization of the OEG layer, end-alkylated
$\mathrm{HA}$ was conjugated to the $\mathrm{EG}_{6} \mathrm{~N}_{3}$ in this OEG layer as indicated by the slight decrease in frequency and increase in dissipation, respectively (Figures 4A,B). Observation of the unspecific attachment of bare liposomes to these surfaces shows a constantly low level with a frequency change of $-5.06 \pm 6.36 \mathrm{~Hz}$ and dissipation change of $2.31 \times 10^{-6} \pm 2.49 \times 10^{-6}$. These signal changes indicate that conjugated HA reduces the unspecific attachment of pure liposomes, which has been detected on the surfaces presenting the RGD motif alone (Figure 4C).

Finally, the effect of the dual-functionalized surface on the adhesion of integrins was investigated. It was observed that the frequency and dissipation changes caused by the binding of proteoliposomes declines with a higher $\mathrm{EG}_{6} \mathrm{~N}_{3}$ content and consequently higher $\mathrm{HA}$ conjugation degree. At an initial $\mathrm{EG}_{6} \mathrm{~N}_{3}$ ratio of $30 \%$, only slight shifts in frequency and dissipation are detected indicating that the adhesion of proteoliposomes fails.

Even at lower ratios of HA between 0.01 and 30\%, fewer proteoliposomes attach to the surface (Figure 4D). Thus, it can be concluded that minimal amounts of conjugated HA are sufficient to prevent the attachment of proteoliposomes to a surface with a constant RGD motif density. In this experiment, sHA molecules with a radius of gyration of around $5.3 \mathrm{~nm}$ were immobilized. Therefore, each conjugated HA molecule covers several molecules in the OEG layer including RGD binding motifs. 


\section{CONCLUSION}

Within this study a biomimetic model was established to address the challenge of co-presenting $\mathrm{HA}$ and the RGD motif to study integrin binding. The adhesion of $\alpha_{\mathrm{IIb}} \beta_{3}$ integrin, which was reconstituted in sphere-shaped lipid vesicles devoid of HA binding proteins, was quantified on HA and the RGD motif functionalized on an otherwise inert background. It is demonstrated that an RGD density of $40 \%$ has to be exceeded to achieve a prominent binding of proteoliposomes. Moreover, it is also concluded that even marginal amounts of HA are sufficient to significantly impact integrin attachment. The dissipation changes indicate that the proteoliposomes maintain an intact vesicle shape. Frohnmayer et al. (2015a,b) demonstrated that the adhesion of similarly prepared proteoliposomes on fibrinogen-coated surfaces, a protein which contains the RGD motif, results in decreased frequency and increased dissipation values within the same order of magnitude monitored in this study.

It would be especially beneficial to use these well-defined dualfunctionalized surfaces to investigate the behavior of various cell lines in future studies. Especially, cancer cell lines are highly interesting since it is known that HA is highly enriched in their ECM. These cell-ECM interactions additionally involve binding of HA with receptors such as CD44 and RHAMM which are

\section{REFERENCES}

Akbarzadeh, A., Rezaei-Sadabady, R., Davaran, S., Joo, S. W., Zarghami, N., Hanifehpour, Y., et al. (2013). Liposome: classification, preparation, and applications. Nanoscale Res. Lett. 8:102. doi: 10.1186/1556-276X-8-102

Almeida, B., and Shukla, A. (2017). Degradation of alkanethiol self-assembled monolayers in mesenchymal stem cell culture. J. Biomed. Mater. Res. A 105, 464-474. doi: 10.1002/jbm.a.35922

Arima, Y., and Iwata, H. (2015). Preferential adsorption of cell adhesive proteins from complex media on self-assembled monolayers and its effect on subsequent cell adhesion. Acta Biomater. 26, 72-81. doi: 10.1016/j.actbio.2015.08.033

Barczyk, M., Carracedo, S., and Gullberg, D. (2010). Integrins. Cell Tissue Res. 339, 269-280. doi: 10.1007/s00441-009-0834-6

Benner, S. A., and Sismour, A. M. (2005). Synthetic biology. Nat. Rev. Genet. 6, 533-543. doi: 10.1038/nrg1637

Berrier, A. L., and Yamada, K. M. (2007). Cell-matrix adhesion. J. Cell. Physiol. 213, 565-573. doi: 10.1002/jcp.21237

Buhler, E., and Boué, F. (2004). chain persistence length and structure in hyaluronan solutions: ionic strength dependence for a model semirigid polyelectrolyte. Macromolecules 37, 1600-1610. doi: 10.1021/ma0215520

Cao, X., Pettit, M. E., Conlan, S. L., Wagner, W., Ho, A. D., Clare, A. S., et al. (2009). Resistance of polysaccharide coatings to proteins, hematopoietic cells, and marine organisms. Biomacromolecules 10, 907-915. doi: 10.1021/bm8014208

Dicker, K. T., Gurski, L. A., Pradhan-Bhatt, S., Witt, R. L., Farach-Carson, M. C., and Jia, X. (2014). Hyaluronan: a simple polysaccharide with diverse biological functions. Acta biomater. 10, 1558-1570. doi: 10.1016/j.actbio.2013.12.019

Dixon, M. C. (2008). Quartz crystal microbalance with dissipation monitoring: enabling real-time characterization of biological materials and their interactions. J. Biomol. Tech. 19, 151-158.

Erb, E. M., Tangemann, K., Bohrmann, B., Muller, B., and Engel, J. (1997). Integrin alphaIIb beta3 reconstituted into lipid bilayers is nonclustered in its activated state but clusters after fibrinogen binding. Biochemistry 36, 7395-7402. doi: 10.1021/bi9702187

Evanko, S. P., Tammi, M. I., Tammi, R. H., and Wight, T. N. (2007). Hyaluronandependent pericellular matrix. Adv. Drug Deliv. Rev. 59, 1351-1365. doi: 10. 1016/j.addr.2007.08.008 associated with tumor progression and metastasis (Liang et al., 2016; Morath et al., 2016; Rankin and Frankel, 2016).

\section{DATA AVAILABILITY}

The raw data supporting the conclusions of this manuscript will be made available by the authors, without undue reservation, to any qualified researcher.

\section{AUTHOR CONTRIBUTIONS}

$\mathrm{HB}, \mathrm{BM}$, and $\mathrm{CZ}$ designed and conceived the experiments. $\mathrm{BM}$ performed preliminary experiments. $\mathrm{CZ}$ performed the experiments and analyzed the data. $\mathrm{CZ}$ and $\mathrm{HB}$ wrote the paper.

\section{ACKNOWLEDGMENTS}

We thank Christine Mollenhauer for the extraction of integrins, Dorothea Brüggemann for fruitful discussions and Prof. Tanaka for providing the NanoZS for DLS measurements. Generous support by Prof. Joachim Spatz and the Max Planck Society is gratefully acknowledged.

Frohnmayer, J. P., Bruggemann, D., Eberhard, C., Neubauer, S., Mollenhauer, C., Boehm, H., et al. (2015a). Minimal synthetic cells to study integrin-mediated adhesion. Angew. Chem. 54, 12472-12478. doi: 10.1002/anie.201503184

Frohnmayer, J. P., Brüggemann, D., Eberhard, C., Neubauer, S., Mollenhauer, C., Boehm, H., et al. (2015b). Synthetische adhäsion von integrin-liposomen als minimales zellmodell. Angew. Chem. 127, 12649-12655. doi: 10.1002/ange. 201503184

Gauthier, N. C., and Roca-Cusachs, P. (2018). Mechanosensing at integrinmediated cell-matrix adhesions: from molecular to integrated mechanisms. Curr. Opin. Cell Biol. 50, 20-26. doi: 10.1016/j.ceb.2017.12.014

Geiger, B., and Yamada, K. M. (2011). Molecular architecture and function of matrix adhesions. Cold Spring Harb. Perspect. Biol. 3:a005033. doi: 10.1101/ cshperspect.a005033

Hanke, M., Hoffmann, I., Christophis, C., Schubert, M., Hoang, V. T., Zepeda-Moreno, A., et al. (2014). Differences between healthy hematopoietic progenitors and leukemia cells with respect to CD44 mediated rolling versus adherence behavior on hyaluronic acid coated surfaces. Biomaterials 35, 14111419. doi: 10.1016/j.biomaterials.2013.11.011

Hao, L., Fu, X., Li, T., Zhao, N., Shi, X., Cui, F., et al. (2016). Surface chemistry from wettability and charge for the control of mesenchymal stem cell fate through self-assembled monolayers. Colloids Surf. B Biointerfaces 148, 549-556. doi: 10.1016/j.colsurfb.2016.09.027

Hu, B., Finsinger, D., Peter, K., Guttenberg, Z., Bärmann, M., Kessler, H., et al. (2000). Intervesicle cross-linking with integrin $\alpha \operatorname{IIb} \beta 3$ and cyclic-RGDlipopeptide. Biochemistry 39, 12284-12294. doi: 10.1021/bi000144q

Hynes, R. O. (2002). Integrins: bidirectional, allosteric signaling machines. Cell 110, 673-687. doi: 10.1016/S0092-8674(02)00971-6

Jansen, K. A., Atherton, P., and Ballestrem, C. (2017). Mechanotransduction at the cell-matrix interface. Semin. Cell Dev. Biol. 71, 75-83. doi: 10.1016/j.semcdb. 2017.07.027

Jeon, H., Simon, C. G., and Kim, G. (2014). A mini-review: cell response to microscale, nanoscale, and hierarchical patterning of surface structure. J. Biomed. Mater. Res. B Appl. Biomater. 102, 1580-1594. doi: 10.1002/jbm.b. 33158

Lee, H., Lee, K., Kim, I. K., and Park, T. G. (2008). Synthesis, characterization, and in vivo diagnostic applications of hyaluronic acid immobilized gold 
nanoprobes. Biomaterials 29, 4709-4718. doi: 10.1016/j.biomaterials.2008. 08.038

Liang, J., Jiang, D., and Noble, P. W. (2016). Hyaluronan as a therapeutic target in human diseases. Adv. Drug Deliv. Rev. 97, 186-203. doi: 10.1016/j.addr.2015. 10.017

Love, J. C., Estroff, L. A., Kriebel, J. K., Nuzzo, R. G., and Whitesides, G. M. (2005). Self-assembled monolayers of thiolates on metals as a form of nanotechnology. Chem. Rev. 105, 1103-1170. doi: 10.1021/cr0300789

Mecham, R. (2011). The Extracellular Matrix: an Overview. Berlin: Springer. doi: 10.1007/978-3-642-16555-9

Minsky, B. B., Antoni, C. H., and Boehm, H. (2016). Controlled immobilization strategies to probe short hyaluronan-protein interactions. Sci. Rep. 6:21608. doi: $10.1038 /$ srep21608

Morath, I., Hartmann, T. N., and Orian-Rousseau, V. (2016). CD44: more than a mere stem cell marker. Int. J. Biochem. Cell Biol. 81, 166-173. doi: 10.1016/j. biocel.2016.09.009

Müller, B., Zerwes, H., Tangemann, K., Peter, J., and Engel, J. (1993). Two-step binding mechanism of fibrinogen to alpha IIb beta 3 integrin reconstituted into planar lipid bilayers. J. Biol. Chem. 268, 6800-6808.

Purnick, P. E. M., and Weiss, R. (2009). The second wave of synthetic biology: from modules to systems. Nat. Rev. Mol. Cell Biol. 10, 410-422. doi: 10.1038/nrm2698

Rankin, K. S., and Frankel, D. (2016). Hyaluronan in cancer - from the naked mole rat to nanoparticle therapy. Soft Matter 12, 3841-3848. doi: 10.1039/c6sm00513f

Streuli, C. H. (2016). Integrins as architects of cell behavior. Mol. Biol. Cell 27, 2885-2888. doi: 10.1091/mbc.E15-06-0369

Takahashi, R., Kubota, K., Kawada, M., and Okamoto, A. (1999). Effect of molecular weight distribution on the solution properties of sodium hyaluronate in $0.2 \mathrm{M} \mathrm{NaCl}$ solution. Biopolymers 50, 87-98. doi: 10.1002/(SICI)10970282(199907)50:1<87::AID-BIP8>3.0.CO;2-K

Tidwell, C. D., Ertel, S. I., Ratner, B. D., Tarasevich, B. J., Atre, S., and Allara, D. L. (1997). Endothelial cell growth and protein adsorption on terminally functionalized. Langmuir 13, 3404-3413. doi: 10.1021/la96 04341

Tu, R. S., and Tirrell, M. (2004). Bottom-up design of biomimetic assemblies. Adv. Drug Deliv. Rev. 56, 1537-1563. doi: 10.1016/j.addr.2003. 10.047

Ventre, M., and Netti, P. A. (2016). Engineering cell instructive materials to control cell fate and functions through material cues and surface patterning. ACS Appl. Mater. Interfaces 8, 14896-14908. doi: 10.1021/acsami.5b0 8658

Yao, X., Peng, R., and Ding, J. (2013). Cell-material interactions revealed via material techniques of surface patterning. Adv. Mater. 25, 5257-5286. doi: 10.1002/adma.201301762

Zaidel-Bar, R., Cohen, M., Addadi, L., and Geiger, B. (2004). Hierarchical assembly of cell-matrix adhesion complexes. Biochem. Soc. Trans. 32(Pt 3), 416-420. doi: 10.1042/BST0320416

Zhang, K., and Chen, J. (2012). The regulation of integrin function by divalent cations. Cell Adh. Migr. 6, 20-29. doi: 10.4161/cam.18702

Zimmerman, E., Geiger, B., and Addadi, L. (2002). Initial stages of cell-matrix adhesion can be mediated and modulated by cell-surface hyaluronan. Biophys. J. 82, 1848-1857. doi: 10.1016/S0006-3495(02)75535-5

Conflict of Interest Statement: The authors declare that the research was conducted in the absence of any commercial or financial relationships that could be construed as a potential conflict of interest.

Copyright (c) 2018 Zapp, Minsky and Boehm. This is an open-access article distributed under the terms of the Creative Commons Attribution License (CC BY). The use, distribution or reproduction in other forums is permitted, provided the original author(s) and the copyright owner(s) are credited and that the original publication in this journal is cited, in accordance with accepted academic practice. No use, distribution or reproduction is permitted which does not comply with these terms. 